\title{
Factors Related to Patient Expectation and Satisfaction among New and Existing Denture wearers with Complete denture therapy
}

Pandey $\mathrm{A}^{1}$

${ }^{1}$ Lecturer, Department of Prosthodontics and Maxillofacial Prosthetics, College of Medical Sciences, Chitwan, Nepal

\begin{abstract}
Introduction: Edentulism is considered a debilitating condition with aging in which several dental and non-dental factors play vital role in the success of prosthodontic treatment. Patient satisfaction is important non-dental component. Dentist should aim for functional rehabilitation by satisfying patient medically, functionally and psychologically. Patient's satisfaction depends on two factors: patient factor and dentist factor. From patient's view, satisfaction is guided by improved quality with factors like eating, easy communication, comfort, social life, economic status and vocational opportunities. From dentist's view, treatment options, treatment cost etc. affects the patient's satisfaction.

Materials and Methods: Experimental study conducted in Department of Prosthodontics, College of Medical Sciences, Bharatpur in patients receiving complete denture by convenience sampling in six months duration in sixty five samples. Questionnaire regarding patient's expectations and satisfaction in terms of retention, mastication, phonetics, esthetics and comfort were used in both $1^{\text {st }}$ time denture wearer and existing denture wearer was recorded. Grading was rated with Visual Analog Scale (VAS) from 0 to 10 using the optimum cutoff values. Data were recorded in SPSS 21 and analyzed.

Results: Independent t-test was carried out for expectation showing statistically significant difference between retention, mastication, aesthetics, phonetics, comfort and denture status with $\mathrm{p}$ value 0.036 , $0.00,0.001,0.003$ and 0.013 respectively. Statistically significant difference was found for satisfaction between aesthetics and denture status with $\mathrm{p}$ value 0.01 .

Conclusions: Expectation and satisfaction was found to be more in first time denture wearers than existing denture wearers. Experiences obtained beforehand with complete dentures could influence patient expectations and satisfaction.
\end{abstract}

Key words: Aesthetics; Complete denture; Mastication; Phonetics.

\section{Introduction}

$\mathrm{C}$ Tonventional complete denture is still regarded as acceptable modality, despite the availability of advanced methods as implants. For achieving optimum retention and stability of full dentures several factors

Conflict of Interest: No

\section{*Corresponding Author}

Dr. Anisha Pandey, Lecturer

Department of Prosthodontics and Maxillofacial

Prosthetics, College of Medical Sciences, Chitwan,

Nepal

E-mail: anisha.reakeey@gmail.com are included. Degree of resorption of alveolar ridges, soft tissue resiliency, neuromuscular coordination, condition of oral mucosa, depth of sulcus and hypertrophy of the tongue are patients' factors. ${ }^{1-6}$ Technical, biological and physiological correlation can fabricate acceptable set of complete denture. ${ }^{7}$ Satisfaction and dissatisfaction also depends upon prosthetic factors like aesthetics, phonetics, mastication, comfort. ${ }^{8-12}$

Mental attitude may also be important for patient acceptance towards new denture. ${ }^{13}$ Several studies show that patient with complete denture therapy get the satisfaction increased with their 
denture after couple of years of insertion. ${ }^{14}$ Patients experience with previous denture have different attitude towards satisfaction.

This study aims to relate the patient's expectation and satisfaction with new and previous denture wearer regarding retention, mastication, aesthetics, phonetics and comfort.

\section{Materials and Methods}

It is an experimental longitudinal study which was conducted for patients receiving Conventional Complete Denture in the Department of Prosthodontics, College of Medical Sciences -TH, Bharatpur in the duration of 6 months ( $1^{\text {st }}$ March 2020 to August $\left.31^{\text {st }} 2020\right)$. Ethical clearance from Institutional Review Board was taken. Informed consent was obtained from the patients prior to study.

Two groups were divided: One with new denture and the other with existing denture wearer. According to the inclusion criteria,

i. Patients with edentulous upper and lower jaw

ii. Patients with age between $38-40$ years

iii. Patients who can understand and respond to the questions asked to them

And exclusion criteria

i. Patients withneurological and psychological disorders.

ii. Patients suffering from acute and chronic symptoms of temporomandibular disorder.

iii. Patients who have undergone jaw surgeries for trauma, cancer, etc.,

Sample size was calculated using following formula:

Sample size $=2 \mathrm{SD}^{2}\left(\mathrm{Z}_{\alpha / 2}+\mathrm{Z}_{\beta}\right)^{2} / \mathrm{d}^{2}$

SD IS 0.45 and $d$ is 0.3 . Therefore, sample size calculated to be 25 in each group with total being 50 . Non-response rate of $25 \%$ was taken therefore being 62.5. Hence, rounding off sample size of 65 was taken.
Before starting the treatment of fabrication of Conventional Complete Denture, a questionnaire was given to them and was explained in the local language or the language in which the patient understands. The patient's expectations regarding retention, mastication, aesthetics, phonetics and comfort was recorded in Visual Analog Scale. It was presented as a $100 \mathrm{~mm}(10 \mathrm{~cm})$ horizontal line on which patients responded to the questionnaire by indicating a position between two end points of the scale.

This was done in both the patients with new denture and that with existing denture with same process and material by the single prosthodontist. After that fabrication of complete denture was done. After one month follow up, patients were given the same questionnaire for the satisfaction of present denture regarding the same aspects.

The results were then statistically analysed. The data collection was done in MS-EXCEL and analysis was done in SPSS 21. Descriptive statistics were used to describe the data and independent t-test was used to find the significant difference for independent groups $\left(1^{\text {st }}\right.$ time denture wearer and existing denture wearer.

\section{Results}

Out of total 65 patients were examined who met the inclusion criteria. $48 \%$ were first time denture wearers while $52 \%$ were existing denture wearers (Figure I).

Of the total participants, majority of them i.e. $53.8 \%$ were females (Figure II).

Overall mean expectation and satisfaction was found to be greater in first time denture wearers than in existing denture wearers as shown in Table I.

Table II shows association of overall mean expectation and satisfaction with gender shows that there was no statistically significant difference between the same. Overall mean 
expectation was found to be lesser in males as compared to females. Also, overall mean expectation was found to be greater than the overall mean satisfaction (Figure III).

Independent t-test was carried out for comparison of expectation of patients with denture status. Statistically significant difference was found to be between retention and denture status $(p=0.036)$, mastication and denture status $(p=0.00)$, aesthetics and denture status $(\mathrm{p}=0.001)$, phonetics and denture status $(\mathrm{p}=0.003)$ and comfort and denture status $(\mathrm{p}=0.013)$ as shown in Table III.

Independentt-test was carried out for comparison of satisfaction of patients with denture status. There was no statistically significant difference between retention and denture status $(\mathrm{p}=0.19)$, mastication and denture status $(p=0.58)$, phonetics and denture status $(\mathrm{p}=0.17)$ and comfort and denture status $(\mathrm{p}=0.11)$. However, statistically significant difference was found to be between aesthetics and denture status as shown in Table IV.

Table 1: Table showing overall mean expectations and satisfaction score among first time denture wearers and existing denture wearers

\begin{tabular}{|l|c|c|}
\hline Overall mean score & & \\
\hline & Expectation & Satisfaction \\
\hline First time denture wearers & 8.1 & 7.0 \\
Existing denture wearers & 7.0 & 6.1 \\
\hline
\end{tabular}

Table 2: Table showing comparison of overall mean expectation and satisfaction with gender

\begin{tabular}{|c|c|c|c|}
\hline & Male & Female & p value \\
\hline Overall mean expectation (SD) & $7.3(1.3)$ & $7.7(1.5)$ & 0.17 \\
\hline Overall mean satisfaction (SD) & $6.1(2.2)$ & $6.9(1.9)$ & 0.15 \\
\hline
\end{tabular}

Table 3: Table showing comparison of expectation of factors among existing denture wearers and first time denture wearers using Independent t-test

\begin{tabular}{|c|c|c|c|c|c|}
\hline \multirow{2}{*}{ Variables } & \multicolumn{2}{|c|}{ First time denture wearer } & \multicolumn{3}{c|}{ Existing denture wearer } \\
\cline { 2 - 7 } & Mean & Standard deviation & Mean & Standard deviation & p value \\
\hline Retention & 8.0 & 1.80 & 7.1 & 1.47 & $0.036^{*}$ \\
Mastication & 8.4 & 1.26 & 7.2 & 1.39 & $0.00^{*}$ \\
Esthetics & 8.5 & 1.78 & 7.0 & 1.66 & $0.001^{*}$ \\
Phonetics & 7.9 & 1.55 & 6.7 & 1.41 & $0.003^{*}$ \\
Comfort & 7.9 & 1.58 & 6.9 & 1.76 & $0.013^{*}$ \\
\hline
\end{tabular}

*Statistically significant with $\mathrm{p}$ value $<0.05$

Table 4: Table showing comparison of satisfaction of factors among existing denture wearers and first time denture wearers using Independent t-test

\begin{tabular}{|c|c|c|c|c|c|}
\hline \multirow{2}{*}{ Variables } & \multicolumn{2}{|c|}{ First time denture wearer } & \multicolumn{3}{c|}{ Existing denture wearer } \\
\cline { 2 - 6 } & Mean & Standard deviation & Mean & Standard deviation & p value \\
\hline Retention & 7.0 & 2.44 & 6.3 & 1.70 & 0.19 \\
Mastication & 6.3 & 2.98 & 6.0 & 1.68 & 0.58 \\
Esthetics & 7.5 & 2.23 & 6.2 & 2.07 & $0.01^{*}$ \\
Phonetics & 7.0 & 2.49 & 6.3 & 1.94 & 0.17 \\
Comfort & 7.0 & 2.80 & 6.0 & 1.96 & 0.11 \\
\hline
\end{tabular}

*Statistically significant with $\mathrm{p}$ value $<0.05$ 


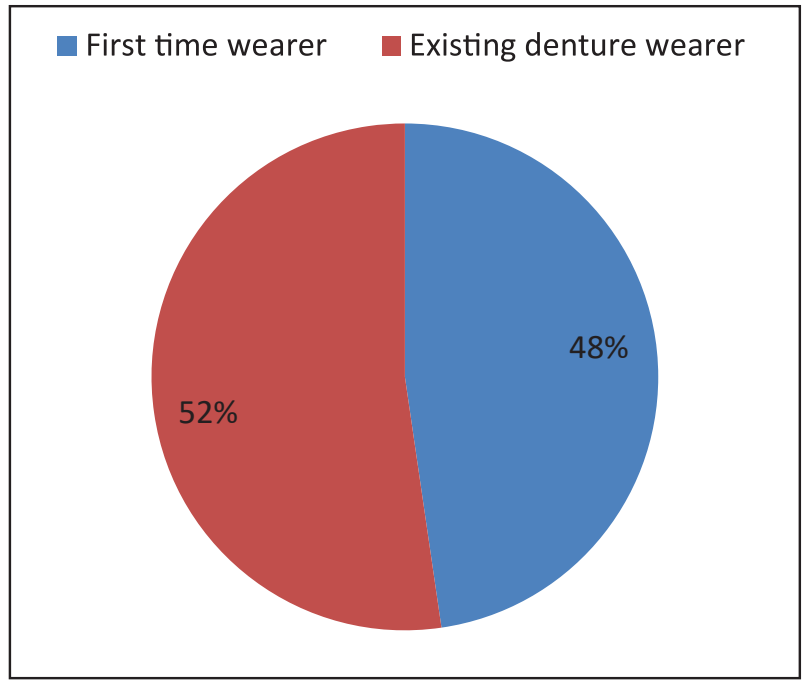

Figure 1: Figure showing distribution of study participants based on denture status

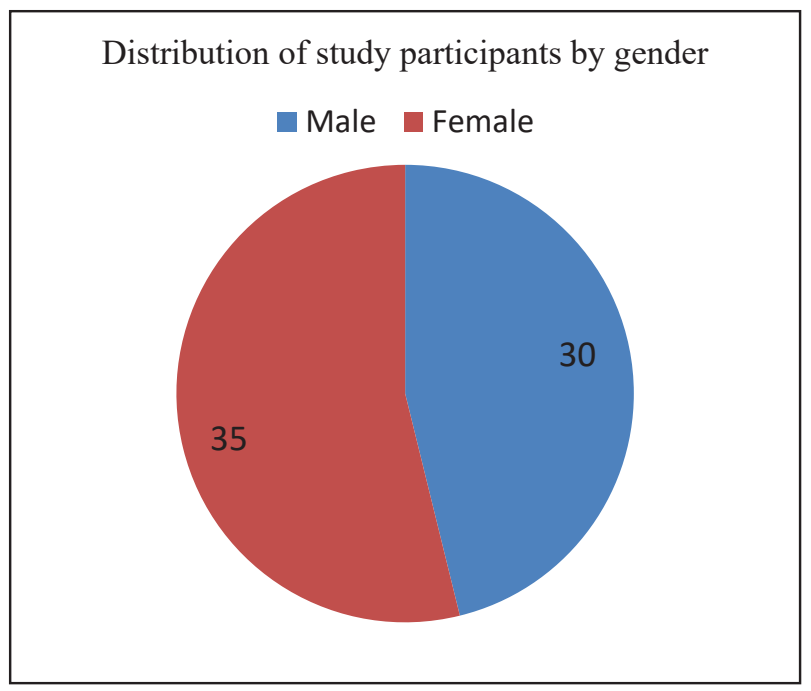

Figure 2: Figure showing distribution of study participants based and gender

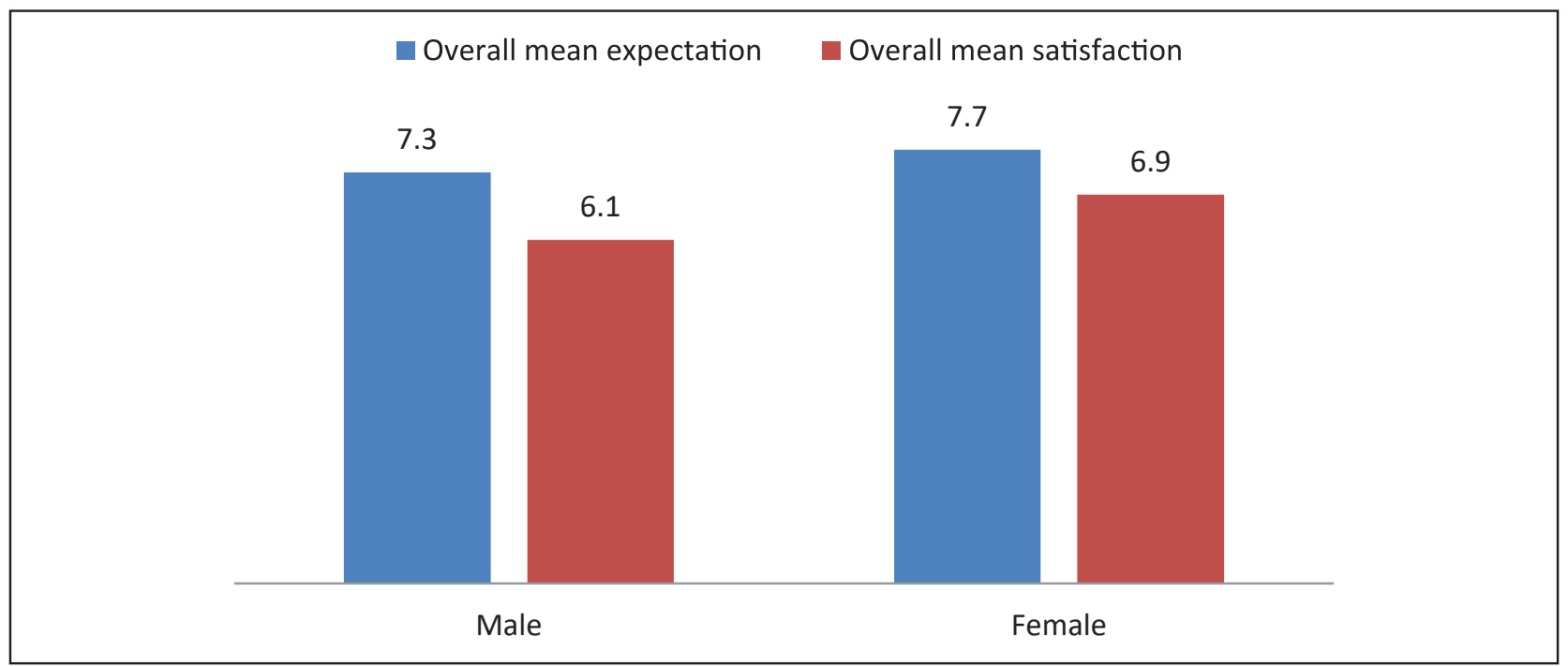

Figure 3: Figure showing comparison of overall mean expectation and satisfaction with gender

\section{Discussion}

Several studies related to satisfaction in complete denture had been conducted. In those studies satisfaction was calculated whereas expectations of the patients prior to treatment were not evaluated. So, in this study we attempt to see the expectation of the patient to meet the satisfaction or not. With the help of questionnaire patient satisfaction which is considered as treatment outcome had been considered. ${ }^{15}$

Existing denture wearers are often difficult to treat and satisfy by the dentist than the first time denture wearer. Therefore, this study helps to find the satisfaction and expectation factors in existing denture wearer and first time denture wearer. Expectation of the patients shows statistically significant difference between the two groups. This might be because patient had no experience about the denture and wants the artificial denture similar to that of natural factors such as mastication, retention, aesthetic, comfort and phonetics are related to satisfaction according to Sato et al. ${ }^{16}$

So, in this study by questionnaire these factors were used. According to these questionnaires fit of the denture(retention), chewing 
efficacy(mastication), appearance(aesthetic), ability to speak (phonetics) and the comfort to wear denture were inquired.

In our study the patient's expectation was higher than the satisfaction after treatment similar to Gasper et al. ${ }^{17}$ Expectation before treatment were higher for all factors in both first time denture wearer and existing denture wearer. It could be because patient was more anxious about their new denture function, comfort and aesthetic. Patient might expect that they could chew similar to their natural teeth as soon as they put on their prosthesis which might not be possible.

This study had shown that expectation of patient in first time denture wearer was more than existing denture wearer. It could be because previous experience of the patient might influence the expectation and satisfaction 17 satisfaction recorded was also more in first time denture wearer than existing denture wearer which might be because they are inexperienced. However statistically significant difference was found in aesthetic and in between two groups. This might be because patients are more concerned about function and comfort rather than aesthetic in contrast with a study by Ellis et.al ${ }^{18}$ which proposed that aesthetic had direct initial impact on satisfaction. In our study female participants are more than male participants which could be one of the reasons for significant difference in aesthetic prior to treatment.

The present study had limited sample size therefore couldn't be representative of all the population of Nepal. So, further studies with larger sample size need to be done.

\section{Conclusions}

Within the limitations of this study, it can be concluded that the expectations in first time denture wearers is greater than satisfaction. Similarly, in existing denture wearer also expectation is greater than satisfaction. However, among the two groups, expectation as well as satisfaction was found to be more in first time denture wearers than existing denture wearers. So we recommend that a clinician should discuss with the patients properly regarding the potential problems and help set the realistic expectations before beginning the treatment.

\section{Acknowledgements}

I would like to acknowledge Dr. Rosina Bhattarai for helping me conduct this study.

\section{References}

1. Burns D, Unger J, Elswick Jr R, Beck D. Prospective clinical evaluation of mandibular implant overdentures: Part I - retention, stability , and tissue response. Maxillofaciial prosthetics Dent Implant. 1995;73(4):354-63.

2. America N, Com- V, Sur- M. Prospective clinical evaluation of mandibular implant overdentures:: Part II - patient satsfaction and preference. J Prosthet Dent. 1994;73(4):364-9.

3. Jeganathan S, Payne JA. Prosthodontics Common faults in complete dentures: A review Prosthodontics. Quintessence Int (Berl). 1993;24(7):483-7.

4. Grasso JE, Rendell J, Gay T. Effect of denture adhesive on the retention and stability of maxillary dentures. J Prosthet Dent. 1994;72(4):399-405.

5. Zlatarić DK, Celebić A, Kobler P. Relationship Between Body Mass Index and Local Quality of Mandibular Bone Structure in elderly individual. Journals Gerontol Ser A Biol Sci Med Sci. 2002;57(9):588-93.

6. Musa I, Knezović-Zlatarić D, Čelebić A, Bošnjak A. The Influence of Gender and Age on the Values of Linear Radiomorphometric Indices Measured on the Lower Border of the Mandible. Acta Stomatol Croat. 2002;36:199202.

7. Berg E. Acceptance of full dentures. Int Dent J. 1993;43:299-306.

8. Marachlioglou CR, Dos Santos JF, Cunha VD, Marchini L. Expectations and final evaluation 
of complete dentures by patients, dentist and dental technician. J Oral Rehabil. 2010;37:51824.

9. Bellini D, Dos Santos MB, De Paula Prisco Da Cunha V, Marchini L. Patients ' expectations and satisfaction of complete denture therapy and correlation with locus of control. J Oral Rehabil. 2009;36:682-6.

10. Baracat LF, Teixeira AM, dos Santos MB, da Cunha VD, Marchini L. Patients' expectations before and evaluation after dental implant therapy. Clin Implant Dent Relat Res. 2011;13(2):141-5.

11. Siqueira GP, Dos Santos MB, Santos JF, Marchini L. Patients' expectation and satisfaction with removable dental prosthesis therapy and correlation with patients' evaluation of the dentists. Acta Odontol Scand. 2013;(August 2011):210-4.

12. Andrade de Lima E, Bertolini Fernandes dos Santos M, Marchini L. Patients' expectations and satisfaction with implant- supported fixed partial dentures and single crowns. Int $\mathbf{J}$ Prosthodont. 2012;25:484-90.

13. Fenlon MR, Sherriff M, Newton JT. The influence of personality on patients ' satisfaction with existing and new complete dentures. J Dent. 2007;35:744-8.

14. Berg E. Influence of some anamnestic, demographic and clinical variables on patient acceptance of full dentures. Acta odontol scand. 1984;4:119-27.

15. Varshney N, Aggarwal S, Kumar S, Singh SP. Retention and patient satisfaction with barclip, ball and socket and kerator attachments in mandibular implant overdenture treatment: An in vivo study. J Indian Prosthodont Soc. 2019;49-57.

16. Sato Y, Hamada S, Akagawa Y, Tsuga K. A method for quantifying overall satisfaction of complete denture patients. J oral Rehabil. 2000;952-7.

17. Gaspar MG, Dos Santos MB, Dos Santos JF, Marchini L. Correlation of previous experience, patient expectation and the number of postdelivery adjustments of complete dentures with patient satisfaction in a Brazilian population. $\mathrm{J}$ Oral Rehabil. 2013;(1):590-4.

18. Ellis JS, Thomason J, McAndrew R. Apilotstudy examining the effects of enhanced aesthetics on oral health related quality of life and patient's satisfaction with complete dentures. Eur J Prosthodont Restor Dent. 2010;18(3):116-22. 